\title{
ANALISIS PENGARUH SISTEM INFORMASI AKUNTANSI PENJUALAN DAN PENERIMAAN KAS TERHADAP SISTEM PENGENDALIAN INTERNAL (STUDI KASUS PADA PT. GOLDENCOMMUNICATION TANJUNG BALAI KARIMUN)
}

\author{
Yusmalina $^{1}$, Sri Elvi Sahfitri ${ }^{2}$, Kasirul Fadli ${ }^{3}$, Ferawaty Tambunan \\ Program Studi Akuntansi, Fakultas Ilmu Sosial dan Humaniora, Universitas Karimun, Provinsi \\ Kepulauan Riau, Indonesia \\ Email : yusmalina8484@gmail.com ${ }^{1}$, elvisahfitri127@gmail.com², fadlly.ahs72@gmail.com ${ }^{3}$
}

\begin{abstract}
Abstrak
Penerapan sistem informasi pada suatu bisnis secara umum dapat meningkatkan keunggulan bersaing (competitive advantage) dengan cara memberikan nilai tambah pada produk dan jasa yang dihasilkannya. Penerapan sistem informasi memerlukan input berupa data dan yang kemudian akan diproses menjadi informasi. Informasi ini nantinya diperlukan perusahaan untuk membantu operasionalnya dan juga dalam pengambilan keputusan. Tujuan dari penelitian ini adalah untuk memperoleh gambaran secara menyeluruh mengenai pengaruh Sistem Informasi Akuntansi Penjualan Dan Penerimaan Kas Terhadap Pengendalian Intern. Penulis dalam melakukan penelitian dengan menggunakan penelitian asosiatif, dengan menggunakan metode kuantitatif. Peneliti menggunakan penelitian asosiatif karena pertanyaan dalam penelitian ini bersifat menanyakan hubungan antara dua variabel dengan prosedur pengumpulan data penelitian lapangan (field research) yang bertujuan untuk memperoleh gambaran yang jelas mengenai penelitian. Dimana pengumpulan data dilakukan melalui wawancara, observasi atau lapangan. Melalui penelitian yang dilakukan penulis, maka didapat hasil antara lain: hasil perhitungan antara variabel independent yaitu Sistem Informasi Akuntansi Penjualan dan Penerimaan Kas serta variabel dependent yaitu Pengendalian Inten. Hasil dari pengujian hipotesis didalam penelitian ini menunjukkan bahwa sistem informasi akuntansi penjualan dan penerimaan kas berpengaruh signifikan dan positif terhadap pengendalian intern.
\end{abstract}

Kata kunci: Sistem Informasi Akuntansi Penjualan, Penerimaan Kas, Pengendalian Intern

\section{PENDAHULUAN}

Konsumen sangat memerlukan informasi untuk menentukan keputusan suatu produk yang akan mereka beli di pasaran. Keputusan yang selalu diharapkan oleh produsen, apakah pesan yang disampaikan lewat promosinya telah dapat terjangkau pasar yang telah diharapkan atau belum. Suatu perusahaan memproduksi barang dengan kualitas yang baik, harga relative mahal, dan tersebar ke berbagai tempat tetapi apabila calon pembeli tidak diberi tahu adanya produk tersebut, diingatkan atau dibujuk untuk membelinya maka produk tersebut tidak akan bisa laku dipasaran.

Proses penjualan yang efektif dan efisien dapat tercapai jika penjualan dilakukan menggunakan aplikasi penjualan. Karena memudahkan dalam mendata barang-barang yang akan dijual atau jumlah stock yang tersedia dengan akurat sehingga memudahkan manajemen untuk mengetahui apakah barang yang dipesan oleh pelanggan tersedia. 
Transaksi yang diinput menggunakan aplikasi penjualan prosesnya sangan cepat sehingga mudah dalam menentukan waktu pembelian. Dengan menggunakan ini, barang-barang yang tersedia atau stock barang dapat dilihat dengan cepat dan akurat, jika stock sudah menipis maka pihak mnajemen akan segera melakukan pembelian.

Dengan menggunakan aplikasi penjualan proses menjadi otomatis karena dengan hanya sekali input maka aplikasi ini dapat menghasilkan output lebih dari satu, jika tidak menggunakan aplikasi penjualan, maka bukan hanya mencatat penjualan secara manual saja, namun hal yang terkait penjualan pun harus dicatat secara manual seperti kartu stock untuk membuat stock update, lalu kartu piutang jika memang penjualannya non tunai, selanjutnya buku kas atau bank jika penjualan tersebut tunai dan sampai harus membuat laporan keuangan seperti neraca serta laporan laba rugi, maka dengan proses pencatatn secara manual menjadi inefisiensi, belum lagi mengenai akurasi dan kecekapatn proses pengerjaan, jadi jika menggunakan aplikasi penjuaalan proses yang lebih dari satu tadi bisa di rampingkan dengan hanya satu kali input penjualan namun output yang terkait dengan proses penjualan lebih dari satu sehingga terciptanya efektif dan efisiensi serta akurasi data.

\section{TINJAUAN PUSTAKA}

\section{Teori Keagenan}

Menurut Jensen dan Meckling (1976) Teori keagenan adalah teori yang menjelaskan mengenai hubungan antara pemilik dan manajemen. Dalam teori agensi menyatakan bahwa apabila terdapat pemisahan antara pemilik sebagai ikeral dan manajer sebagai agen yang menjalankan perusahaan, maka akan muncul permasalahan agensi karena masing-masing pihak baik ikeral dan manajer akan selalu berusaha untuk memaksimalkan fungsi utilitasnya

\section{Sistem Informasi Akuntansi}

Menurut (Bodnar dan Hopwood, 2012:1). sistem informasi akuntansi merupakan sistem yang menyediakan informasi akuntansi dan keuangan beserta informasi lainnya yang di peroleh dari proses rutin transaksi akuntansi. Informasi- informasi yang dihasilkan oleh sistem informasi akuntansi antara lain meliputi informasi mengenai order penjualan, penjualan, penerimaan kas, order pembelian, pembayaran, dan penggajian. Sistem informasi akuntansi adalh kumpulan sumber daya, orang-orang tersebut dan peralatan, yang dirancang untuk mengubah data keuangan dan lainnya menjadi informasi (Bodnar dan Hopwood, 2012:1).

\section{Penjualan}

Menurut Basu Swastha defini penjualan adalah sebagai berikut: "Penjualan adalah ilmu dan seni mempengaruhi pribadi yang dilakukan oleh penjual untuk mengajak orang lain agar bersedia membeli barang atau jasa yang ditawarkan “.(1999:8).

\section{Sistem Akuntansi Penerimaan Kas}

Pengertian sistem akuntansi penerimaan kas menurut Mulyadi (2011:456) "Sistem akuntansi penerimaan kas adalah satu jaringan prosedur yang dibuat menurut pola yang 
terpadu untuk melaksanakan kegiatan penerimaan kas dari penjualan rutin dan tidak rutin berdasarkamm ketentuan-ketentuan dari perusahaan yang bersangkutan.

\section{Sistem Pengendalian Internal}

Menurut I Gusti Agung Rai (2008: 283) pengertian pengendalian intern adalah sebagai berikut: "Sistem pengendalian intern adalah kebijakan dan prosedur yang dirancang untuk memberikan keyakinan yang memadai bagi manajemen bahwa organisasi mencapai tujuan dan sasarannya."

\section{Kerangka Konseptual}

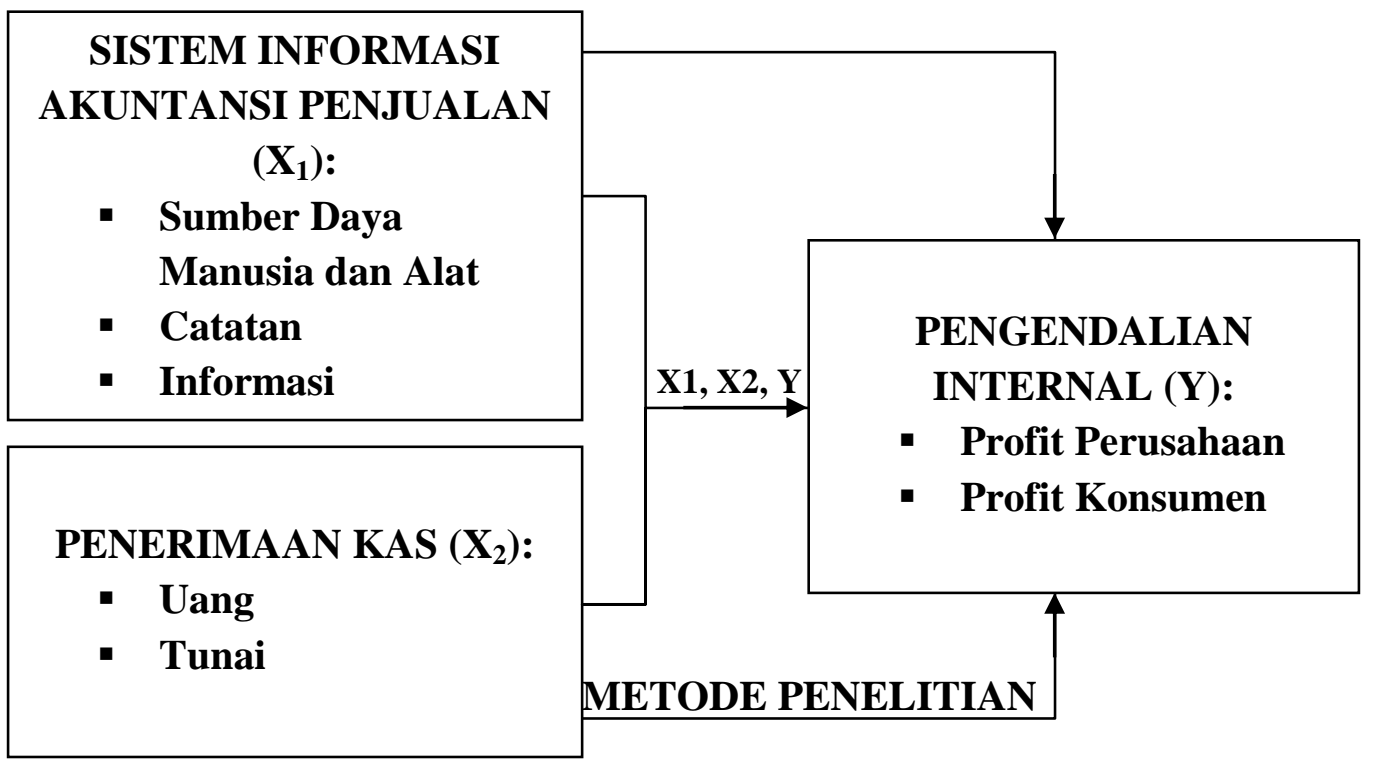

Metode penelitian yang digunakan peneliti adalah metode analisis kuantitatif, yaitu menekankan analisisnya pada data numerical atau angka yang diperoleh dengan metode statistic serta dilakukan pada penelitian inferensial atau dalam rangka pengujian hipotesis sehingga diperoleh signifikan hubungan antara variabel .

\section{Populasi}

Menurut Sugiyono (2013) populasi adalah wilayah generalisasi yang terdiri atas obyek/ subyek yang mempunyai kuantitas dan karakteristik tertentu yang ditetapkan oleh peneliti untuk dipelajari dan kemudian ditarik kesimpulannya. Populasi bukan hanya orang, tetapi juga obyek dan benda-benda alam yang lain. Populasi juga bukan sekedar jumlah yang ada pada obyek atau subyek yang dipelajari, tetapi meliputi seluruh karakteristik/sifat yang dimiliki oleh subyek atau obyek itu. Penelitian menggunakan seluruh karyawan PT.Golden Communication sebagai responden, karena jumlah karyawan yang akan dijadikan responden 30 orang. 
III. HASIL DAN PEMBAHASAN

\section{Hasil Uji Reliabilitas Variabel Sistem Informasi Akuntansi Penjualan $\left(\mathbf{X}_{1}\right)$}

\begin{tabular}{|l|r|r|r|r|}
\hline \multicolumn{5}{|c|}{ Item-Total Statistics } \\
& $\begin{array}{c}\text { Scale Mean if } \\
\text { Item Deleted }\end{array}$ & $\begin{array}{c}\text { Scale } \\
\text { Variance if } \\
\text { Item Deleted }\end{array}$ & $\begin{array}{c}\text { Corrected } \\
\text { Item-Total } \\
\text { Correlation }\end{array}$ & $\begin{array}{c}\text { Cronbach's } \\
\text { Alpha if Item } \\
\text { Deleted }\end{array}$ \\
\hline Item1 & 93.17 & 110.968 & .532 & .705 \\
Item2 & 93.43 & 112.075 & .535 & .707 \\
Item3 & 93.48 & 114.897 & .477 & .713 \\
Item4 & 93.04 & 112.316 & .408 & .710 \\
Item5 & 93.35 & 112.964 & .521 & .709 \\
Item6 & 92.96 & 115.134 & .435 & .714 \\
Item7 & 93.09 & 115.810 & .365 & .717 \\
Item8 & 93.13 & 115.755 & .380 & .717 \\
Item9 & 93.04 & 114.225 & .386 & .714 \\
Item10 & 93.13 & 114.482 & .386 & .714 \\
Item11 & 92.61 & 115.794 & .366 & .717 \\
Item12 & 93.17 & 113.787 & .483 & .711 \\
Item13 & 93.39 & 112.158 & .604 & .706 \\
Item14 & 93.00 & 115.545 & .367 & .716 \\
Item15 & 93.04 & 116.134 & .377 & .717 \\
SkorTotal & 48.17 & 30.423 & 1.000 & .777 \\
\hline
\end{tabular}

Berdasarkan hasil perhitungan dengan bantuan program SPSS 17.0 di atas terlihat bahwa nilai Cronbach's Alpha dari 23 orang responden untuk 15 item pernyataan yang ada dalam variabel Sistem Informasi Akuntansi Penjualan masing-masing memiliki tingkat reliabilitas lebih besar dari 0,60, sehingga dapat disimpulkan bahwa sebanyak 15 pernyataan dalam variabel Sistem Informasi Akuntansi Penjualan tersebut sudah reliabel.

\section{Hasil Uji Reliabilitas Variabel Pengendalian Intern (Y)}

\begin{tabular}{|l|r|r|r|r|}
\hline \multicolumn{5}{|c|}{ Item-Total Statistics } \\
\hline & $\begin{array}{c}\text { Scale Mean if } \\
\text { Item Deleted }\end{array}$ & $\begin{array}{c}\text { Scale } \\
\text { Variance if } \\
\text { Item Deleted }\end{array}$ & $\begin{array}{c}\text { Corrected } \\
\text { Item-total } \\
\text { Correlation }\end{array}$ & $\begin{array}{c}\text { Cronbach's } \\
\text { Alpha if Item } \\
\text { Deleted }\end{array}$ \\
\hline Item1 & 94.74 & 146.383 & .504 & .719 \\
Item2 & 94.83 & 145.423 & .510 & .717 \\
Item3 & 95.04 & 150.407 & .469 & .725 \\
Item4 & 94.61 & 147.431 & .406 & .722 \\
Item5 & 94.87 & 146.300 & .552 & .718 \\
Item6 & 94.43 & 146.621 & .613 & .717 \\
Item7 & 94.61 & 150.976 & .378 & .727 \\
Item8 & 94.39 & 143.976 & .546 & .714 \\
Item9 & 94.61 & 148.794 & .425 & .724 \\
Item10 & 94.57 & 145.893 & .568 & .717 \\
Item11 & 94.17 & 150.877 & .392 & .727 \\
Item12 & 94.74 & 148.656 & .505 & .722 \\
Item13 & 94.96 & 148.134 & .545 & .721 \\
Item14 & 94.57 & 150.439 & .402 & .726 \\
Item15 & 94.61 & 151.067 & .418 & .727 \\
SkorTotal & 48.96 & 39.498 & 1.000 & .814 \\
\hline
\end{tabular}

Berdasarkan hasil perhitungan dengan bantuan program SPSS 17.0 di atas terlihat bahwa Cronbach's Alpha dari 23 orang responden untuk 15 item pernyataan yang ada 
dalam variabel Pengendalian Intern masing-masing memiliki tingkat reliabilitas lebih besar dari 0,60, sehingga dapat disimpulkan bahwa sebanyak 15 pernyataan dalam variabel Pengendalian Intern tersebut sudah reliabel.

\section{Hasil Output Regression Coefficients}

\begin{tabular}{|c|c|c|c|c|c|c|}
\hline \multicolumn{7}{|c|}{ Coefficients $^{a}$} \\
\hline \multirow{2}{*}{\multicolumn{2}{|c|}{ Model }} & \multicolumn{2}{|c|}{ Unstandardized Coefficients } & \multirow{2}{*}{$\begin{array}{c}\begin{array}{c}\text { Standardized } \\
\text { Coefficients }\end{array} \\
\text { Beta } \\
\end{array}$} & \multirow[b]{2}{*}{$t$} & \multirow[b]{2}{*}{ Sig. } \\
\hline & & $\mathrm{B}$ & Std. Error & & & \\
\hline \multirow[t]{3}{*}{1} & (Constant) & -4.690 & 2.769 & & -1.694 & .106 \\
\hline & $\begin{array}{l}\text { Sistem Informasi } \\
\text { Akuntansi }\end{array}$ & 1.165 & .400 & 1.023 & 2.910 & .009 \\
\hline & Penerimaan Kas & -.051 & .380 & -.047 & -.135 & .894 \\
\hline
\end{tabular}

a. Dependent Variable: Pengendalian Intern

Berdasarkan tabel Output Regression Coefficients, maka model persamaan regresi linier berganda adalah sebagai berikut:

$$
\mathrm{Y}=4,690+1,165 \mathrm{X}_{1}+0,051 \mathrm{X}_{2}+\mathrm{e}
$$

Dalam persamaan ini besarnya konstanta semuanya bernilai positif ini menunjukkan nilai koefisien variabel bebas yaitu Sistem Informasi Akuntansi Penjualan $\left(\mathrm{X}_{1}\right)$ dan Penerimaan Kas $\left(\mathrm{X}_{2}\right)$ menunjukkan pengaruh positif terhadap Pengendalian Intern (Y).

\section{Hasil Uji-t (Coefficients)}

Uji Analisis Parsial (Uji t)

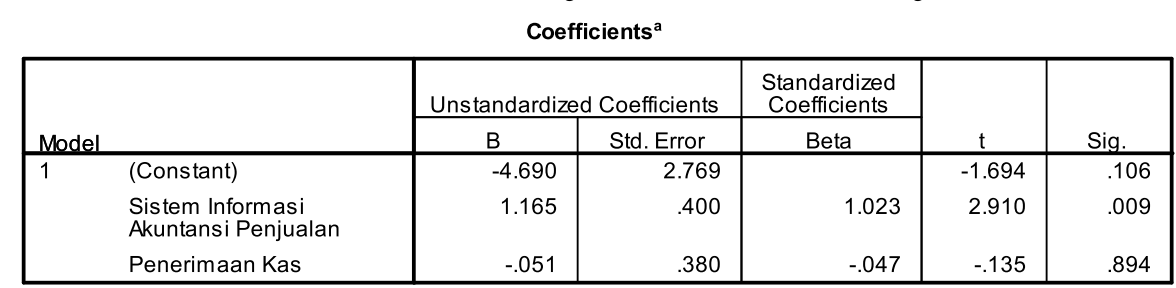

a. Dependent Variable: Sistem Pengendalian Internal

\section{Uji F (Uji Simultan)}

\begin{tabular}{|c|c|c|c|c|c|c|}
\hline \multicolumn{7}{|c|}{ ANOVA $^{b}$} \\
\hline \multicolumn{2}{|c|}{ Model } & $\begin{array}{c}\text { Sum of } \\
\text { Squares }\end{array}$ & df & Mean Square & $\mathrm{F}$ & Sig. \\
\hline \multirow[t]{3}{*}{1} & Regression & 827.456 & 2 & 413.728 & 199.386 & $.000^{\mathrm{a}}$ \\
\hline & Residual & 41.500 & 20 & 2.075 & & \\
\hline & Total & 868.957 & 22 & & & \\
\hline
\end{tabular}

a. Predictors: (Constant), Penerimaan Kas, Sistem Informasi Akuntansi

b. Dependent Variable: Pengendalian Intern

Dari tabel diatas dapat dilihat nilai $\mathrm{F}$ statistik sebesar 0,000 yang berarti nilai $\mathrm{F}$ statistik $<0,05$ artinya terdapat pengaruh yang signifikan secara simultan antara variabel bebas terhadap variabel terikat. 


\section{Hasil Analisis Koefisien Determinasi $\left(\mathbf{R}^{2}\right)$}

\begin{tabular}{|c|c|r|r|r|r|}
\hline \multicolumn{1}{|c|}{ Model Summary $^{\mathbf{b}}$} \\
\hline Model & $\mathrm{R}$ & R Square & $\begin{array}{c}\text { Adjusted R } \\
\text { Square }\end{array}$ & $\begin{array}{c}\text { Std. Error of } \\
\text { the Estimate }\end{array}$ & $\begin{array}{c}\text { Durbin- } \\
\text { Watson }\end{array}$ \\
\hline 1 & $.976^{\mathrm{a}}$ & .952 & .947 & 1.440 & 1.264 \\
\hline
\end{tabular}

a. Predictors: (Constant), Penerimaan Kas, Sistem Informasi Akuntansi

b. Dependent Variable: Pengendalian Intern

Diketahui angka $\mathrm{R}$ sebesar 0,976 atau $97,6 \%$ artinya korelasi antara variabel Sistem Informasi Akuntansi Penjualan dengan Efektivitas Pengendalian Internal Penjualan terjadi hubungan yang erat karena nilai $\mathrm{R}$ mendekati 1 . Dari pengujian tersebut juga dapat dilihat besarnya $\mathrm{R}$ Square 0,952 atau 95,2\%. Hal ini berarti Sistem Informasi Akuntansi Penjualan menjelaskan terhadap Pengendalian Internal Penjualan dengan besar pengaruh 0,952 atau 95,2\%. Dengan demikian tinggi rendahnya pengendalian internal penjualan dipengaruhi oleh sistem informasi akuntansi penjualan sebesar 95,2\% sedangkan sisanya 4,8\% dijelaskan faktor lain diluar model.

\section{Pembahasan Hasil Analisa Data}

Dari penelitian yang dilakukan peneliti melalui kuesioner, diperoleh hasil sistem informasi akuntansi penjualan berpengaruh signifikan terhadap efektivitas pengendalian internal penjualan hal ini dapat dilihat dari hasil uji t dimana variabel pengendalian intern memiliki $t_{\text {hitung }}=2,910$ dan $t_{\text {table }}(\alpha=0,05 ; \mathrm{df}=23)$ adalah sebesar 2.07961. Karena $t_{\text {hitung }}>t_{\text {table }}$ yaitu 2,910 $>2.08596$ atau nilai signifikan yaitu 0,009 lebih kecil dari 0,05 maka hipotesis diterima, yaitu sistem informasi akuntansi penjualan dan penerimaan kas berpengaruh positif terhadap pengendalian internal penjualan.

Berdasarkan hasil analisis regresi juga dapat diketahui bahwa peran sistem informasi akuntansi penjualan dan penerimaan kas memiliki nilai positif dan signifikan terhadap pengendalian internal penjualan, dengan nilai koefisien sebesar 0,976, jadi pengendalian internal penjualan dapat dipengaruhi secara signifikan oleh sistem informasi akuntansi penjualan dan penerimaan kas dengan tingkat pengaruh sebesar $95,2 \%$.

Dari hasil penelitian yang dilakukan Flowchart Penjualan Perusahaan PT. Golden Communication Tanjung Balai Karimun masih sederhana tetapi secara umum dapat dikatakan cukup baik, meskipun proses penjualan yang dilakukan dengan cara manualisasi, tetapi tidak semuanya manual masih ada penggunaan komputer sebagai alat bantu untuk mencetak dokumen-dokumen tersebut yaitu dengan menggunakan Microsoft excel. Pada sistem penjualan perusahaan ini masih terdapat kekurangan yang sekiranya perlu diperbaiki lagi. Adapun pada bagian marketing penjualan tidak melakukan pengecekan PO tetapi langsung diproses lanjut sehingga memungkin kan terjadinya kesalahan adminitrasi. Kemudian hal yang perlu diperhatikan adalah pada bagian gudang dan pengiriman tidak dilakukan secara terpisah, ini memungkinkan akan terjadinya kecurangan dan kesalahan dalam proses pengarsipan maupun pengiriman barang. Dan ada hal yang lain perlu ditambah yaitu bagian penagihan ini Karena bagian ini akan sangat berguna pada saat proses pembayaran dan pada saat dokumen-dokumen tersebut dibuat sebagai tanda bukti saat proses penagihan. Dan perlu diperhatikan juga 
untuk tugas-tugas dari masing-masing bagian penjualan, ini perlu diperhatikan supaya dalam kegiatan penjualan akan lebih aman dan efektif dalam kegiatan penjualan.

Sedangkan Flowchart penjualan yang baik yaitu dengan adanya pemisahan tugas antara yang mengelolah bagian marketing penjualan, bagian gudang, bagian pengiriman serta bagian keuangan agar tidak terjadi kecurangan dan kesalahan dalam proses kegiatan perusahaan sehingga akan lebih aman dan efektif dalam kegiatan penjualan.

\section{KESIMPULAN}

Adapun beberapa saran yang ingin penulis sarankan dalam penelitian ini adalah:

1. Pemisahan fungsi kas dengan fungsi akuntansi. Sehingga fungsi kas hanya menerima pembayaran dari customer dan menyetorkan ke bank. Sedangkan untuk pencatatan sebaiknya dilakukan oleh karyawan lain, bisa dengan menambah karyawan baru khusus bagi pencatatan dan pembukuan atau diserahkan ke bagian administration and finance coordinator.

2. Dalam penerbitan kuitansi tercetak rangkap 4, sebaiknya cukup menerbitkan rangkap 3. Rangkap 1 untuk customer, rangkap 2 untuk bagian kasir dan rangkap 3 untuk bagian pencatatan atau pembukuan dalam sistem akuntansi penjualan dan penerimaan kas.

3. Dalam prosedur penjualan yang diterapkan, bagian sales menuju kasir terlebih dahulu sebelum dibuatnya nomor ID customer oleh bagian koordinator after sales service, seharusnya bagian sales menuju ke bagian koordinator after sales service dulu untuk pembuatan ID customer baru menuju sales karena no. ID berguna sebagai delivery order dan customer.

4. Kas atau uang yang diterima dari cutomer, seharusnya disetorkan pada hari yang sama saat kas diterima atau selambat-lambatnya pagi pada hari kerja berikutnya, agar tidak terjadi penumpukan kas dan penyalahgunaan kas yang dapat merugikan perusahaan.

5. Pemisahan fungsi kas dengan fungsi akuntansi. Sehingga fungsi kas hanya menerima pembayaran dari customer dan menyetorkan ke bank. Sedangkan untuk pencatatan sebaiknya dilakukan oleh karyawan lain, bisa dengan menambah karyawan baru khusus bagi pencatatan dan pembukuan atau diserahkan ke bagian administration and finance coordinator.

6. Dalam penerbitan kuitansi tercetak rangkap 4, sebaiknya cukup menerbitkan rangkap 3. Rangkap 1 untuk customer, rangkap 2 untuk bagian kasir dan rangkap 3 untuk bagian pencatatan atau pembukuan dalam sistem akuntansi penjualan dan penerimaan kas.

7. Dalam prosedur penjualan yang diterapkan, bagian sales menuju kasir terlebih dahulu sebelum dibuatnya nomor ID customer oleh bagian koordinator after sales service, seharusnya bagian sales menuju ke bagian koordinator after sales service dulu untuk pembuatan ID customer baru menuju sales karena no. ID berguna sebagai delivery order dan customer.

8. Kas atau uang yang diterima dari cutomer, seharusnya disetorkan pada hari yang sama saat kas diterima atau selambat-lambatnya pagi pada hari kerja berikutnya, agar tidak terjadi penumpukan kas dan penyalahgunaan kas yang dapat merugikan perusahaan 


\section{DAFTAR PUSTAKA}

Warren,Reeve, dan Fess. (2008). Accounting (pengantar akuntansi), Buku Satu Edisi 2, Salemba Empat, Jakarta.

Siregar Syofian. (2013). Metode penelitian kuantitatif: dilengkapi dengan perbandingan perhitungan manual SPSS. Kencana, Jakarta.

Ikatan Akuntansi Indonesia. (2007). Standar Akuntansi Keuangan. Jakarta : Salemba Empat .

Mulyadi, (2001). Sistem Akuntansi, Edisi Ketiga, Cetakan Ketiga, Penerbit Salemba Empat, Jakarta.

Parnami dan Damayanthi. (2014). Penilaian Efektivitas Sistem Informasi Akuntansi Berbasis Komputer pada Dinas Perindustrian dan Perdagangan Provinsi Bali. EJurnal Akuntansi Universitas Udayana. 6.3. Hal 370-378 dalam www.portalgaruda.org diakses 11 Desember 2015.

Santoso, Slamet. (2015). Penelitian Kuantitatif Metode dan Langkah Pengolahan Data. Penerbit Unmuh Ponorogo Press, Ponorogo.

Widiastuti (2015). Sistem Informasi Akuntansi Berbasis Komputer. Issn: 2337-523x. Bhirawa.Vol. 2. No. 2 dalam E-Journal.stie-aub.ac.id diakses 11 Desember 2015.

Widiastuti (2015). Sistem Informasi Akuntansi Berbasis Komputer. Issn: 2337-523x. Bhirawa.Vol. 2. No. 2 dalam E-Journal.stie-aub.ac.id diakses 11 Desember 2015.

Sugiyono. (2010). Metode penelitian bisnis. Bandung. Alfabeta

Sugiyono. (2013). Metode penelitian kuantitatif kualitatif R\&D. Bandung. Alfabeta

Lyan (2012). Sistem Informasi Akuntansi. Diambil dari http://esterlyan92.blogspot.co.id/2012/04/siklus-pendapatan.html?m=1, pada tanggal 16 Oktober 2016.

Krismiaji (2002). Sistem Informasi Akuntansi. Penerbit dan Percetakan AMP YKPN, Yogjakarta.

Adibah, Dzulkirom, Husaini, (2015). Analisis Sistem Akuntansi Penjualan dan Penerimaan Kasdalam Upaya Pengendalian Intern. Jurnal Adminitrasi Bisnis (JAB). Vol. 26 No. 1 September 2015. diakses 04 Juni 2016.

Ardana dan Lukman (2016). Sistem Informasi Akuntansi. Penerbit Mitra Wacana Media. Isbn: 978-602-318-046-2. Edisi Pertama, Jakarta.

Hartono, Jogiyanto. (1989). Analisis dan Disain, ANDI, Yogyakarta

Andi Kristanto. (2003). Perancangan Sistem Informasi dan Aplikasinya, GAVA MEDIA Yogyakarta

Wijayanto Nugroho. (2001). Sistem Informasi Akuntansi; editor Yati Sumiharti, Jakarta: Erlangga. 